\title{
CLINICAL AND FUNCTIONAL OUTCOMES OF PATIENTS UNDERTAKING POSTERIOR CRUCIATE LIGAMENT (PCL) RECONSTRUCTION USING STANDARD AND POSTEROMEDIAL PORTAL FIXATION
}

\author{
Dyah Paramita'), Rhatomy Solahudin²) \\ ${ }^{1)}$ Department of Orthopedics and Traumatology, Dr. Sardjito General Hospital/ \\ Faculty of Medicine, Universitas Gadjah Mada, Yogyakarta, Indonesia \\ ${ }^{2)}$ Department of Orthopedics and Traumatology, Dr. Soeradji Tirtonegoro Hospital, \\ Klaten, Central Java, Indonesia
}

\begin{abstract}
Background: Currently handling patients with posterior cruciate ligament (PCL) injury is still controversial. Arthroscopic techniques can reduce surgical morbidity and allow for an earlier and aggressive rehabilitation program. This study aimed to evaluate the clinical and functional outcomes of patients with isolated PCL ruptures undergoing PCL reconstruction with PCL residual, tendon hamstring autopsies, standard portable interference fixation, and posteromedial.

Subjects and Method: This was a retrospective cohort study conducted at Dr. Soeradji Tirtonegoro Hospital, Klaten, Central Java. A total sample of 6 patients with isolated PCL rupture was selected for this study. The independent variables were PCL reconstruction with PCL residual, autologous tendon hamstring, standard portal interference fixation, and posteromedial for 9 months (range 5-17 months). The dependent variable was clinical and functional outcomes, which were measured by the International Knee Documentation Committee (IKDC), Knee Society Score, Tigner Lysholm Knee rating scale, and a modified Cincinnati Assessment System Questionnaire. Scores of clinical and functional outcomes before and after surgery were tested by t-test.

Results: The Tigner score after surgery (mean $=94.50 ; \mathrm{SD}=4.18)$ was higher than before surgery (mean $=63.17 ; \mathrm{SD}=12.48$ ) with $\mathrm{p}=0.001$. The IKDC score after surgery $($ mean $=81.48 ; \mathrm{SD}=10.12)$ was higher than before surgery (mean= 55.73; $\mathrm{SD}=18.72)$ with $\mathrm{p}=0.014$. Cincinnati modification score after operation $($ mean $=92.83 ; \mathrm{SD}=8.11)$ higher than before surgery $($ mean $=66.17 ; \mathrm{SD}=13.23)$ with $\mathrm{p}=0.002$. The Knee Society Score after surgery (mean=82.16; $\mathrm{SD}=4.91$ ) was higher than before surgery $($ mean $=60.83 ; \mathrm{SD}=10.51)$ with $\mathrm{p}=0.001$. The percentage of patients with knee stability according to Lysholm score after surgery (6 patients, 100\%) was higher than before surgery (3 patients, 50\%).

Conclusion: PCL reconstruction with PCL residual, autologous tendon hamstring, standard portal interference fixation, and posteromedial for 9 months can improve clinical and functional outcomesin patients with isolated PCL rupture.
\end{abstract}

Keywords: posterior cruciate ligament, portal posteromedial, reconstruction

\section{Correspondence:}

Paramita Dyah Lasmana. Department of Orthopedics and Traumatology, Dr. Sardjito General Hospital/Faculty of Medicine, Universitas Gadjah Mada, Yogyakarta, Indonesia. Email: meetha_dyah@yahoo.com.

Mobile: +6282137543690.

Mid-International Conference on Public Health, Best Western Premier Hotel, Solo, Indonesia, 18-19 April 2018 | 242 https://doi.org/10.26911/mid.icph.2018.05.04 